\title{
Experimental Assessment of the Equivalent Strain Rate for an Instrumented Charpy Test
}

\author{
Enrico Lucon \\ National Institute of Standards and Technology, \\ Boulder, CO, 80305 \\ enrico.lucon@nist.gov
}

Instrumented Charpy test data can be used to obtain estimates of dynamic yield strength, by means of a well-established relationship published by W. Server in 1978. A fundamental issue in comparing measured dynamic tensile properties and Charpy-based estimations is establishing the equivalent uniaxial strain rate for an instrumented Charpy test, typically conducted at $\approx 5.5 \mathrm{~m} / \mathrm{s}$. In this investigation, by performing tensile tests at various strain rates and instrumented Charpy tests for 10 different materials, we compared values of dynamic yield strength both measured from tensile tests and estimated by means of Server's equation. The obtained equivalent Charpy strain rates were found to vary significantly from material to material, and to correlate reasonably with specific values of absorbed energy measured during the impact tests.

Key words: Charpy impact test; dynamic tensile testing; strain rate; tensile behavior; yield strength.

Accepted: March 30, 2016

Published: April 13, 2016

http://dx.doi.org/10.6028/jres.121.007

\section{Introduction}

Instrumented impact testing is often considered to be a relatively recent technical development of Charpy testing, even though the earliest known paper dealing with force measurements during an impact test [1] actually predates the first pendulum machine publication [2] by one year. In actual fact, instrumented Charpy testing started to gain popularity in the technical community in the early 1920s, when it was still considered a sort of laboratory curiosity [3]. It was, however, in the 1950s and 1960s that the scientific community recognized that a more accurate understanding of the dynamic fracture process could be achieved only by instrumenting the pendulum machine, and specifically by applying strain-gages to the striker in order to determine force/time test records. From force and time measurements, it was then possible to derive specimen deflection by simple calculation of velocity and acceleration, and ultimately to obtain the energy absorbed by the specimen during the fracture process.

The analysis of an instrumented Charpy test consists in the determination of characteristic time, force, displacement, and absorbed energy values corresponding to general yield, maximum force, initiation of unstable fracture, arrest of unstable fracture, and test termination (Fig. 1).

These events are not identifiable in all tests. Fully brittle specimens, representative of lower shelf behavior, do not exhibit general yield, and typically maximum force coincides with the initiation of unstable fracture. Furthermore, the force at crack arrest is normally equal to zero. Fully ductile specimens, representative of upper shelf behavior, do not exhibit unstable fracture or crack arrest.

An important application of the characteristic force at general yield $\left(F_{g y}\right)$, proposed by Server in 1978 [4], is the estimation of dynamic yield strength $\left(\sigma_{Y S d}\right)$ based on $F_{g y}$ values. The dynamic yield strength of a material is of particular importance for loading-rate sensitive materials such as low strength steels. Typical applications of $\sigma_{Y S d}$ values include the characterization of steels for the automotive and aircraft industries, structural assessments of pressure vessels, and other circumstances where high loading rates and impact events are possible during operation. 


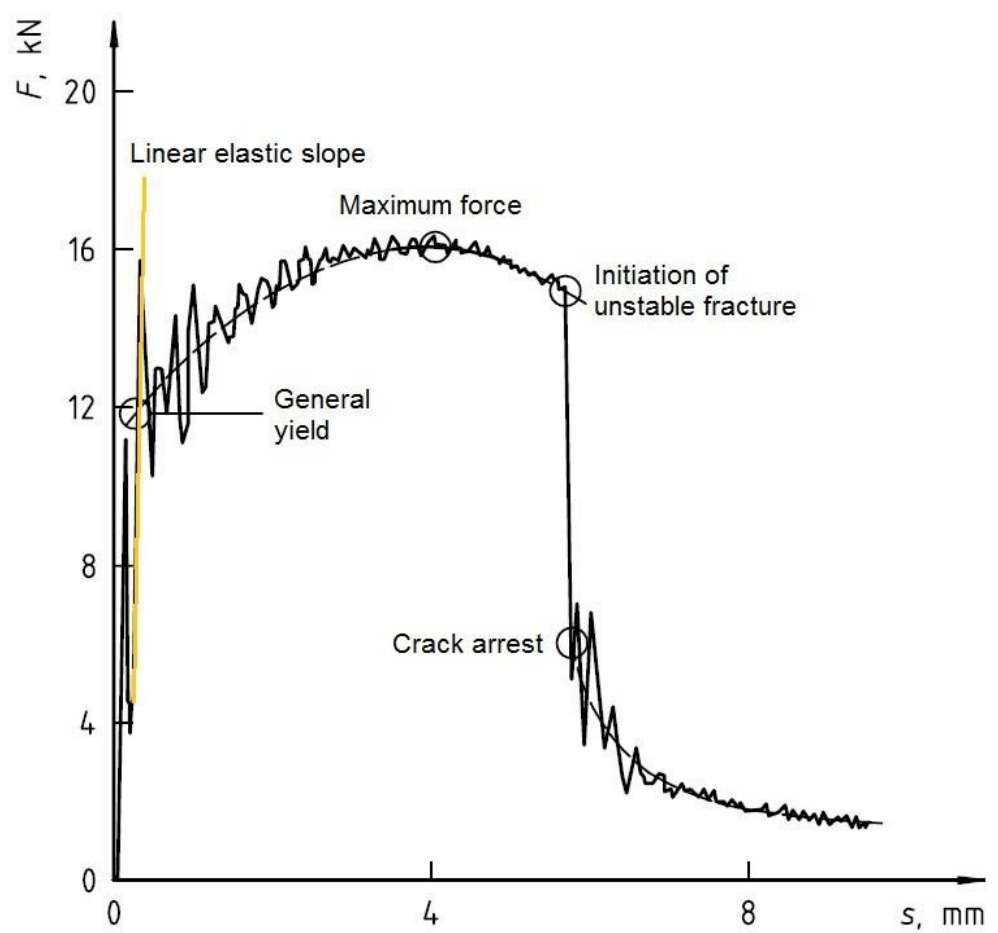

Fig. 1. Example of instrumented Charpy test record for a specimen tested in ductile-to-brittle transition regime.

\section{Estimation of Dynamic Yield Strength from the Force at General Yield}

On an instrumented force/time or force/displacement record (Fig. 1), general yield (GY) corresponds to the point where plastic yielding spreads across the whole unnotched ligament of the specimen.

In 1978, Server proposed the following relationship for estimating the dynamic yield strength of a metallic material based on the force at general yield $F_{G Y}[4]$ :

$$
\sigma_{G Y}=\frac{3.732 F_{G Y} W}{C_{G Y} B(W-a)^{2}}
$$

where: $W, B$, and $a$ are specimen width, thickness, and notch depth, and the constraint factor at general yield, $C_{G Y}$, depends on the shape of the indenter (i.e., the radius of the striking edge) and the root radius of the notch [5-7]. $C_{G Y}$ values for different strikers (striking edge radius: $2 \mathrm{~mm}$ or $8 \mathrm{~mm}$ ) and Charpy specimen types (V-notched and precracked) are given in Table 1.

Table 1. Values of the constraint factor $C_{G Y}$ at general yield for different striker and specimen types.

\begin{tabular}{|ccc|}
\hline $\begin{array}{c}\text { Striking edge } \\
\text { radius (mm) }\end{array}$ & $\begin{array}{c}\text { Specimen } \\
\text { type }\end{array}$ & $C_{G Y}$ \\
\hline 2 & V-notched & 1.274 \\
\cline { 2 - 3 } 2 & Precracked & 1.279 \\
\hline \multirow{2}{*}{8} & V-notched & 1.336 \\
\cline { 2 - 3 } & Precracked & 1.402 \\
\hline
\end{tabular}

In this investigation, we tested $\mathrm{V}$-notched specimens by means of a pendulum machine equipped with an $8 \mathrm{~mm}$ instrumented striker. Inserting from Table $1 C_{G Y}=1.336$ in Eq. (1), we obtain: 


$$
\sigma_{G Y}=\frac{2.793 F_{G Y} W}{B(W-a)^{2}}
$$

and finally, assuming nominal dimensions for the specimen $(W=B=10 \mathrm{~mm}, a=2 \mathrm{~mm})$ :

$$
\sigma_{G Y}=43.65 F_{G Y} \text {. }
$$

with $F_{G Y}$ expressed in $\mathrm{kN}$ and $\sigma_{G Y}$ expressed in MPa. $\sigma_{G Y}$ is an estimate of the dynamic yield strength $\sigma_{Y S d}$ of the material at a uniaxial strain rate corresponding to the loading rate of the instrumented Charpy tests.

\section{Uniaxial Strain Rate Corresponding to a Charpy Test}

Very disparate values have been proposed in the literature for the equivalent uniaxial strain rate $\left(\dot{\varepsilon}_{e q}\right)$ of a typical Charpy test, conducted with an impact speed between $5 \mathrm{~m} / \mathrm{s}$ and $5.5 \mathrm{~m} / \mathrm{s}$.

In Ref. [4], Server reports values of $\dot{\varepsilon}_{\text {eq }}$ between $10^{2} \mathrm{~s}^{-1}$ and $10^{3} \mathrm{~s}^{-1}$ at general yield [8-10]. The main difficulty in assessing $\dot{\varepsilon}_{\text {eq }}$ is represented by the large difference between the very high plastic strain rate at the notch and the much lower plastic strain rate in the plastic hinge. Server obtained the following relationship between equivalent elastic strain rate and specimen deflection rate $\dot{s}$ :

$$
\dot{\varepsilon_{e q}}=164 \dot{s}
$$

with $\dot{\varepsilon}_{\text {eq }}$ expressed in $\mathrm{s}^{-1}$ and $\dot{s}$ expressed in $\mathrm{m} / \mathrm{s}$. For a mild steel tested at room temperature at an impact speed of $5.18 \mathrm{~m} / \mathrm{s}$, the deflection rate is $\dot{s} \approx 1.68 \mathrm{~m} / \mathrm{s}$, which yields a value of the equivalent elastic strain rate $\dot{\varepsilon}_{\text {eq }} \approx 276 \mathrm{~s}^{-1}$. This value remains approximately the same for precracked specimens tested at a lower velocity $(1.22 \mathrm{~m} / \mathrm{s})$.

Depending on whether the equivalent Charpy strain rate is evaluated at the notch root or averaged across the whole specimen ligament, very different values of $\dot{\varepsilon}_{\text {eq }}$ have been suggested:

- for the equivalent (average) strain rate at the notch root: values on the order of $10^{3} \mathrm{~s}^{-1}$, based on 3-D finite element analyses of the Charpy impact test [11-14];

- for the equivalent strain rate averaged across the whole specimen ligament: $\dot{\varepsilon}_{\text {eq }} \approx 10 \mathrm{~s}^{-1}$, based on the comparison between the results of dynamic tensile tests and instrumented Charpy tests for a number of nuclear-grade pressure vessel steels $[15,16]$.

Furthermore, two ASTM fracture toughness standards (E1820 and E1921) provide equations to estimate the approximate equivalent strain rate to be used for dynamic tensile testing when analyzing the results of elevated loading rate toughness tests.

ASTM E1820-15a includes the following formula in Annex A14 (Special Requirements for Rapid-Load J-Integral Fracture Toughness Testing):

$$
\dot{\varepsilon}_{e q}=\frac{2 \sigma_{Y S}}{t_{Q} E}
$$


where: $\sigma_{Y S}=$ quasi-static yield strength at the temperature of the fracture test, $t_{Q}=$ time to the onset of fracture instability or to the initiation of stable crack extension, and $E=$ Young's modulus at the temperature of the fracture test.

Another annex of E1820, Annex A17 (Fracture Toughness Tests at Impact Loading Rates Using Precracked Charpy-Type Specimens), provides the following, almost identical, equation:

$$
\dot{\varepsilon}_{e q}=\frac{2 \sigma_{Y S}}{\overline{t E}} .
$$

Here, $\bar{t}$ is the time to fracture in case of linear elastic behavior (small-scale yielding), or the time corresponding to the initial linear part of the force-time record in the case of elastoplastic material behavior.

Finally, Annex A1 of E1921-15 (Special Requirements for Determining the Reference Temperature, $T_{0, X}$, at Elevated Loading Rates) provides the following relationship:

$$
\dot{\varepsilon}_{e q}=\frac{2 \sigma_{Y S} \dot{K}_{I}}{\overline{K_{J C}} E}
$$

where: $\dot{K}_{I}=$ average loading rate of the elevated rate tests, and $\overline{K_{J c}}=$ average cleavage toughness of the elevated rate tests.

Note that, since the loading rate is calculated in practice as the ratio between $K_{J c}$ and the time to cleavage, Eq. (7) effectively reduces to Eq. (5) or Eq. (6) with $t_{Q}$ or $\bar{t}$ corresponding to the time to cleavage. The three equations provided in E1820 and E1921 derive from the same two references, Irwin [17] and Shoemaker [18].

One of the objectives of this investigation was the assessment of the experimental equivalent strain rate of Charpy tests for several steels, by comparing the results of dynamic tensile tests conducted at different strain rates and the estimates of dynamic yield strength obtained from instrumented Charpy tests by means of Eqs. (2) or (3). The experimental values of $\dot{\varepsilon}_{\text {eq }}$ were also compared with published values and estimates yielded by Eqs. (5), (6), and (7).

\section{Materials and Experiments}

Eight steels corresponding to a wide range of tensile and fracture properties have been tested in this work. Their chemical composition and basic mechanical properties are listed in Table 2 and Table 3, respectively.

Table 2. Chemical composition of the investigated steels (weight \%).

\begin{tabular}{|cccccccccccc|}
\hline Steel & $\mathrm{C}$ & $\mathrm{Mn}$ & $\mathrm{S}$ & $\mathrm{P}$ & $\mathrm{Si}$ & $\mathrm{Cr}$ & $\mathrm{Ni}$ & $\mathrm{Mo}$ & $\mathrm{Cu}$ & $\mathrm{V}$ & $\mathrm{Nb}$ \\
\hline A709 & 0.13 & 1.05 & 0.030 & 0.013 & 0.33 & 0.50 & 0.08 & 0.03 & 0.32 & 0.022 & 0.003 \\
\hline 73W & 0.098 & 1.56 & 0.005 & 0.005 & & 0.25 & 0.60 & 0.58 & 0.31 & 0.003 & \\
\hline 2205 Duplex SS & $\leq 0.03$ & $\leq 2.0$ & $\leq 0.015$ & $\leq 0.030$ & $\leq 1.0$ & 22 & 5 & 3.2 & & & \\
\hline A36 & 0.049 & 0.58 & 0.008 & 0.009 & 0.27 & 0.75 & 0.86 & 0.19 & 1.16 & 0.003 & 0.036 \\
\hline API X100 & 0.07 & 1.83 & 0.005 & 0.005 & 0.11 & 0.03 & 0.52 & 0.27 & 0.30 & & 0.027 \\
\hline 4340-LL & \multirow{2}{*}{0.4} & \multirow{2}{*}{0.66} & \multirow{2}{*}{0.001} & \multirow{2}{*}{0.004} & 0.28 & \multirow{2}{*}{0.83} & \multirow{2}{*}{1.77} & \multirow{2}{*}{0.28} & & & \\
\hline 4340-HH & & & & & & & & & & \\
\hline T-200 $^{\mathbf{1}}$ & $\leq 0.01$ & $\leq 0.01$ & $\leq 0.01$ & $\leq 0.01$ & $\leq 0.01$ & & 18.5 & 3.0 & & & \\
\hline
\end{tabular}

\footnotetext{
${ }^{1}$ Nominal chemical composition.
} 
Table 3. Basic mechanical properties of the investigated steels.

\begin{tabular}{|c|c|c|c|c|}
\hline Steel & $\begin{array}{c}\sigma_{Y S} \\
(\mathrm{MPa})\end{array}$ & $\begin{array}{c}\sigma_{T S} \\
(\mathrm{MPa})\end{array}$ & $\begin{array}{c}\varepsilon_{t} \\
(\%)\end{array}$ & $\begin{array}{l}K V \\
\text { (J) }\end{array}$ \\
\hline A709 & 378 & 583 & 22 & 123 \\
\hline $73 \mathrm{~W}$ & 496 & 674 & 19 & 95 \\
\hline 2205 Duplex SS & 588 & 860 & 25 & 356 \\
\hline A36 & 259 & 423 & 36 & 193 \\
\hline API X100 (or. L) & 756 & 870 & 6 & 441 \\
\hline API X100 (or. T) & 887 & 906 & 14 & 255 \\
\hline $4340-\mathrm{LL}$ & 1348 & 1529 & 5 & 21 \\
\hline $4340-\mathrm{HH}$ & 909 & 1050 & 21 & 110 \\
\hline T-200 (SH-37) & 930 & 1012 & 22 & 249 \\
\hline T-200 (SH-38) & 1012 & 1170 & 17 & 173 \\
\hline
\end{tabular}

LEGEND $\sigma_{Y S}, \sigma_{T S}, \varepsilon_{t}$ : yield strength, tensile strength, and elongation at fracture at quasi-static strain rates $\left(10^{-4} \mathrm{~s}^{-1}\right.$ to $\left.10^{-3} \mathrm{~s}^{-1}\right)$ and room temperature; $K V$ : Charpy absorbed energy at room temperature.

Based on the information provided in Table 3, the steels investigated cover a wide range of basic mechanical properties, namely:

- $\quad$ room temperature quasi-static yield strengths between $259 \mathrm{MPa}$ and $1348 \mathrm{MPa}$;

- room temperature quasi-static tensile strengths between $423 \mathrm{MPa}$ and $1529 \mathrm{MPa}$;

- room temperature quasi-static elongations at fracture between $5 \%$ and $36 \%$;

- room temperature Charpy energies between $21 \mathrm{~J}$ and $441 \mathrm{~J}$.

\subsection{Tensile Tests}

Tensile testing on the investigated steels was carried out partly at Colorado School of Mines (CSM) in Golden, Colorado and partly at NIST in Boulder, Colorado. All tests were conducted in actuator displacement control (i.e., using a constant speed of the machine actuator), but while CSM tests on A36, X100 and SH-37 were performed without extensometer, specimens tested at NIST (for all the remaining materials) were instrumented with an axial extensometer having sufficient travel ( $1 \mathrm{in} .=25.4 \mathrm{~mm})$ to cover specimen elongation up to fracture.

All testing was performed at room temperature $\left(21^{\circ} \mathrm{C} \pm 2{ }^{\circ} \mathrm{C}\right)$, using ASTM E8/E8M-type specimens with round cross section and diameter of the gage section $D=2.5 \mathrm{~mm}$ (SH-37), $D=4 \mathrm{~mm}$ (X100 and A36), or $D=3 \mathrm{~mm}$ (all remaining materials). In order to effectively characterize the strain rate dependence of the materials, tensile tests were performed at multiple strain rates ranging from $10^{-4} \mathrm{~s}^{-1}$ to $10^{1} \mathrm{~s}^{-1}$. Several approaches were considered for the assessment of the effective strain rate corresponding to the yield force and the maximum force, as discussed below.

\subsubsection{Establishment of the Uniaxial Strain Rate for the Tensile Tests}

For tensile tests conducted without extensometer, the nominal strain rate, $\varepsilon_{\text {nom }}$, can be calculated by dividing the actuator displacement rate by the length of the specimen reduced section, under the (reasonable) assumption that, up to maximum force, plastic strain is homogeneously distributed along the entire reduced section of the specimen. A more accurate calculation is obtained by linearly fitting $N$ values of force as a function of the corresponding time values ( $N$-point average method). In this investigation, we used $N=9$. For the generic $i^{\text {th }}$ data point in the raw data file, the instantaneous estimated strain rate $\dot{\varepsilon}_{\text {est }, i}$ corresponds to the slope of the straight line that fits displacement and force data points between $[i-(N-1) / 2]=i-4$ and $[i+(N-1) / 2]=i+4$, with $N=9$. It was found that, for slow tests (strain rate on the order of $10^{-3} \mathrm{~s}^{-1}$ to $10^{-4} \mathrm{~s}^{-1}$ ), the strain rate is reasonably constant (see Fig. 2(a) for a slow T-200 test), while for fast tests it takes almost half of the test duration for the strain rate to reach a relatively steady level, and both the yield point and the maximum force are located in the portion where strain rate is still increasing (see Fig. 2b for a fast T-200 test). 


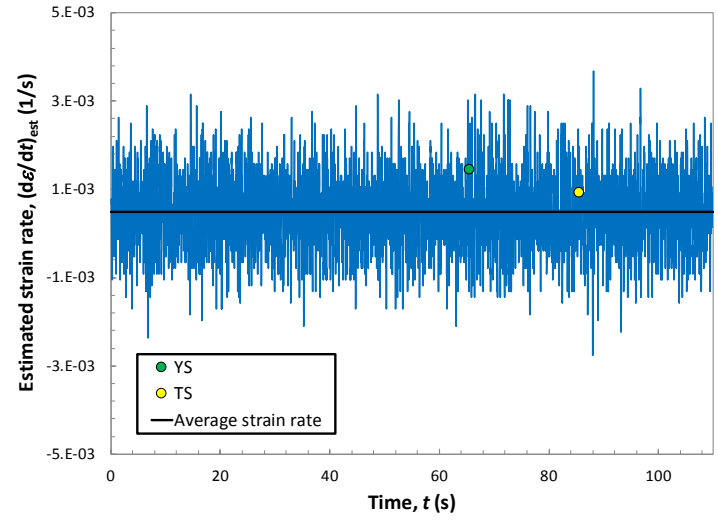

(a)

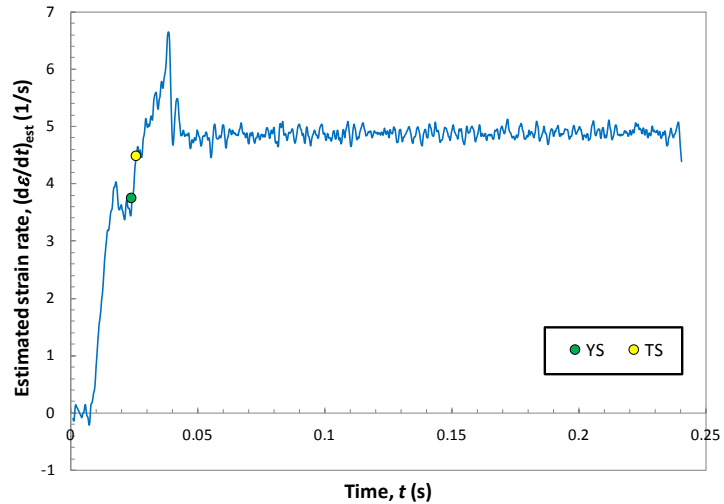

(b)

Fig. 2. Estimated strain rates (using the 9-point average method) for a slow (a) and a fast (b) tensile test on T-200 (SH37), conducted without extensometer. The green and yellow symbols indicate yield strength (YS) and tensile strength (TS), respectively.

For the tests conducted with extensometer, the nominal strain rate can still be obtained by dividing the imposed actuator displacement rate by the length of the reduced section. The effective point-by-point strain rate was obtained by applying the linear fitting method described above to values of time and specimen elongation (extensometer signal), with $N=9$. Slow tests (see Fig. 3(a) for a slow 73W test) exhibited large oscillations of the effective strain rate, partly due to the Portevin-Le Chatelier (PLC) effect $[19,20]$ which occurs at $10^{-4} \mathrm{~s}^{-1}$ (more details are given below). In the case of fast tests (see Fig. 3(b) for a fast 73W test), where the test duration is on the order of a tenth of a second, the effective strain rate doesn't actually reach a stable state, and exhibits significant oscillations in the early part, where the yield point is located. Note also that negative values of strain rate in the early portion of the test are most likely due to extensometer slippage (see Sec. 4.1.2 for more details).

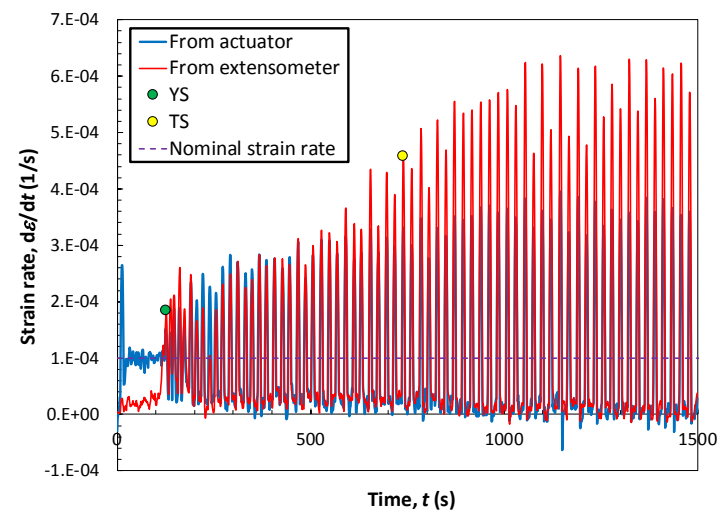

(a)

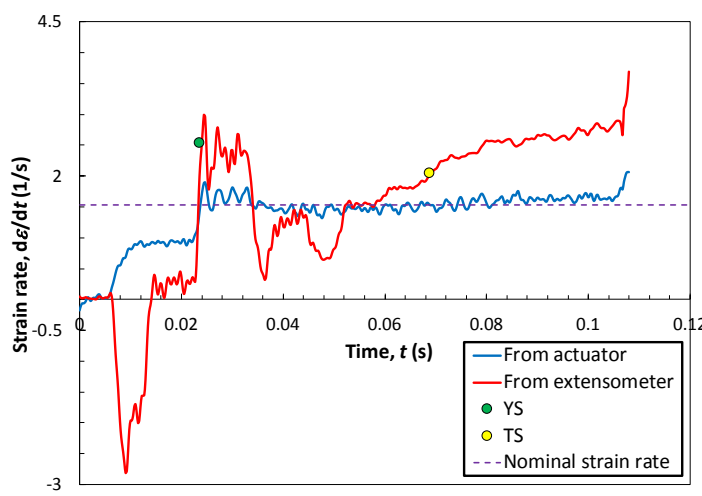

(b)

Fig. 3. Calculated strain rates (using the 9-point average method on actuator and extensometer data) for a slow (a) and a fast (b) tensile test on 73W. The green and yellow symbols indicate yield strength (YS) and tensile strength (TS), respectively.

An overall comparison between extensometer-based and actuator-based strain rate, both calculated by means of the nine-point average method, was conducted on the six tensile tests performed on 73W. In all cases, the strain rate derived by the extensometer signal kept increasing up to specimen failure due to strain localization during necking, whereas that obtained by actuator displacement tends to stabilize around the nominal value after the onset of plastic deformation (i.e., after yielding). In Fig. 4, the two calculations of strain rate are compared to the nominal values for all tests performed on 73W: for both yield and ultimate 


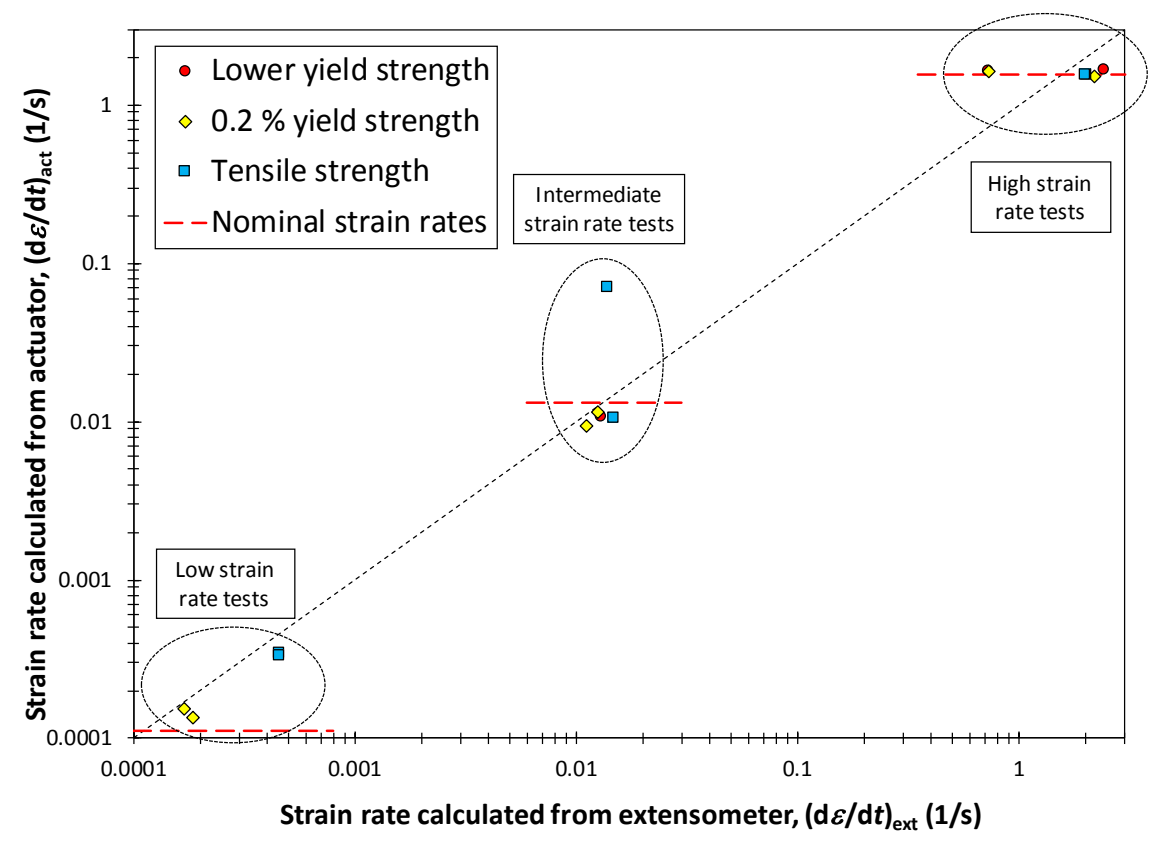

Fig. 4. Comparison between extensometer-based and actuator-based strain rates for all tests on 73W.

tensile strength, actuator-based strain rates were in good agreement with extensometer-based strain rates (which are associated to significant uncertainties for fast tests).

Under the reasonable assumption that the observations for $73 \mathrm{~W}$ can be generalized to all the other materials tested with extensometer, and for the sake of consistency with those steels that were tested without extensometer (A36, X100 or. L and T, and SH-37), we decided to use the actuator-based strain rate, calculated with the 9-point average method, for all subsequent analyses.

\subsubsection{Additional Remarks on the Tensile Tests}

As mentioned above, the tensile tests conducted on all steels at strain rates on the order of $10^{-4} \mathrm{~s}^{-1}$ exhibited serrated stress-strain curves of the type shown in Fig. 5, due to the occurrence of the PLC effect.

The PLC effect has been long associated with dynamic strain aging, or the competition between diffusing solutes, pinning dislocations, and dislocations breaking free of this stoppage. This process starts at a critical strain, which is both temperature and strain rate dependent [21]. Since the PLC effect only appears when inhomogeneous deformation starts, it doesn't significantly affect the yield strength of the material.

Four of the steels tested (A709, 73W, A36, and X100 or. T) exhibited discontinuous yielding for some or all of the specimens tested. Discontinuous or non-uniform yielding is typically associated with Lüders bands (localized bands of plastic deformation), which are common in low-carbon steels. Similar to the PLC effect, they are caused by the pinning of dislocations by interstitial atoms, typically carbon and nitrogen [21].

In case of discontinuous yielding, it is common practice to report the minimum value of engineering stress during the period of discontinuous yielding, which is known as lower yield strength $\left(\sigma_{L Y S}\right)$, as the value of yield strength. When no discontinuous yielding is observed, the measured yield strength corresponds to the engineering stress at a plastic (irreversible) strain equal to $0.2 \%$ of the extensometer gage length, $\sigma_{Y S 0.2}$. For the tests conducted without extensometer, an estimate of $\sigma_{Y S 0.2}\left(\sigma_{Y S 0.2(\text { est })}\right)$ can be obtained from the force/actuator displacement curve, after linearly fitting the initial portion and neglecting any early non-linearities. We have observed that for the six steels tested at NIST with extensometer, measured values of $\sigma_{Y S 0.2}$ and $\sigma_{Y S 0.2(e s t)}$ were in close agreement, as shown in Fig. 6. For the vast majority (91\%) of the tests considered, the two values agree within $\pm 5 \%$. The three remaining data points fall well within $\pm 10 \%$, and all correspond to strain rates greater than $1 \mathrm{~s}^{-1}$. 


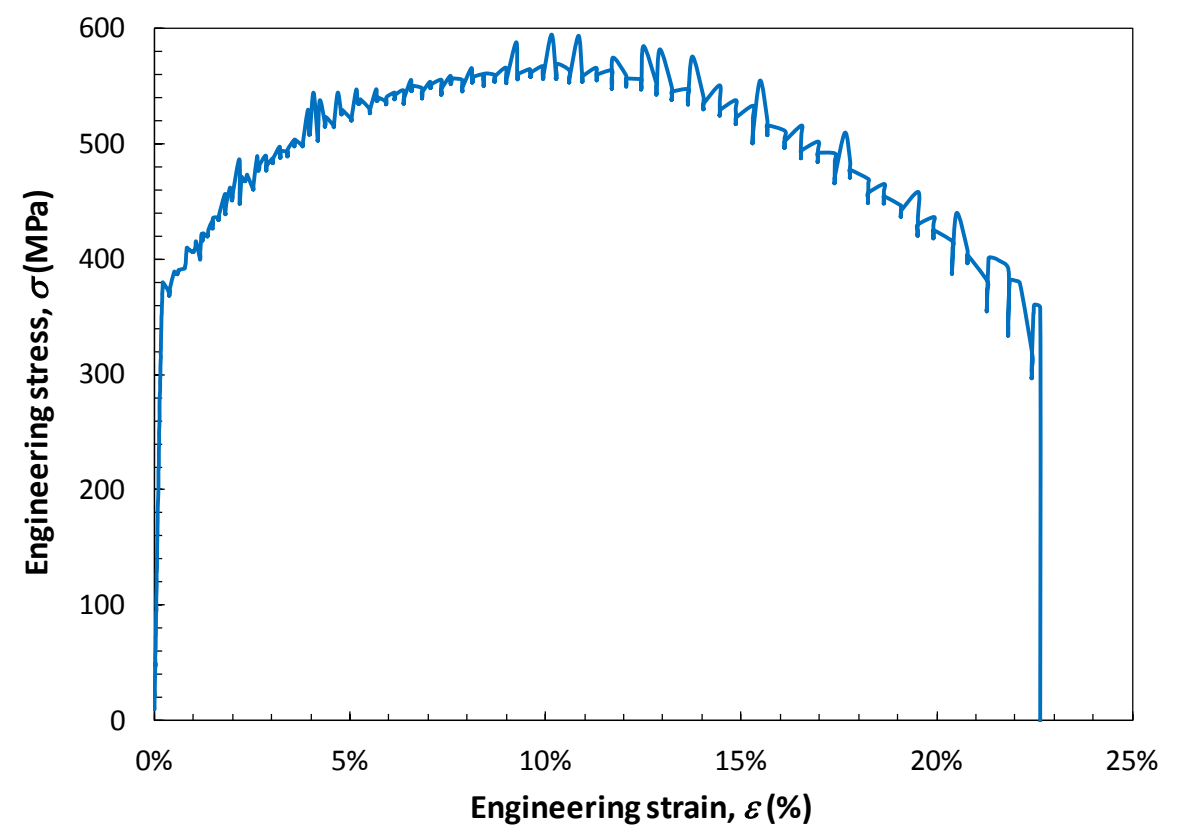

Fig. 5. Engineering stress-strain curve for A709 tested at a nominal strain rate of $10^{-4} \mathrm{~s}^{-1}$, showing the PLC effect.

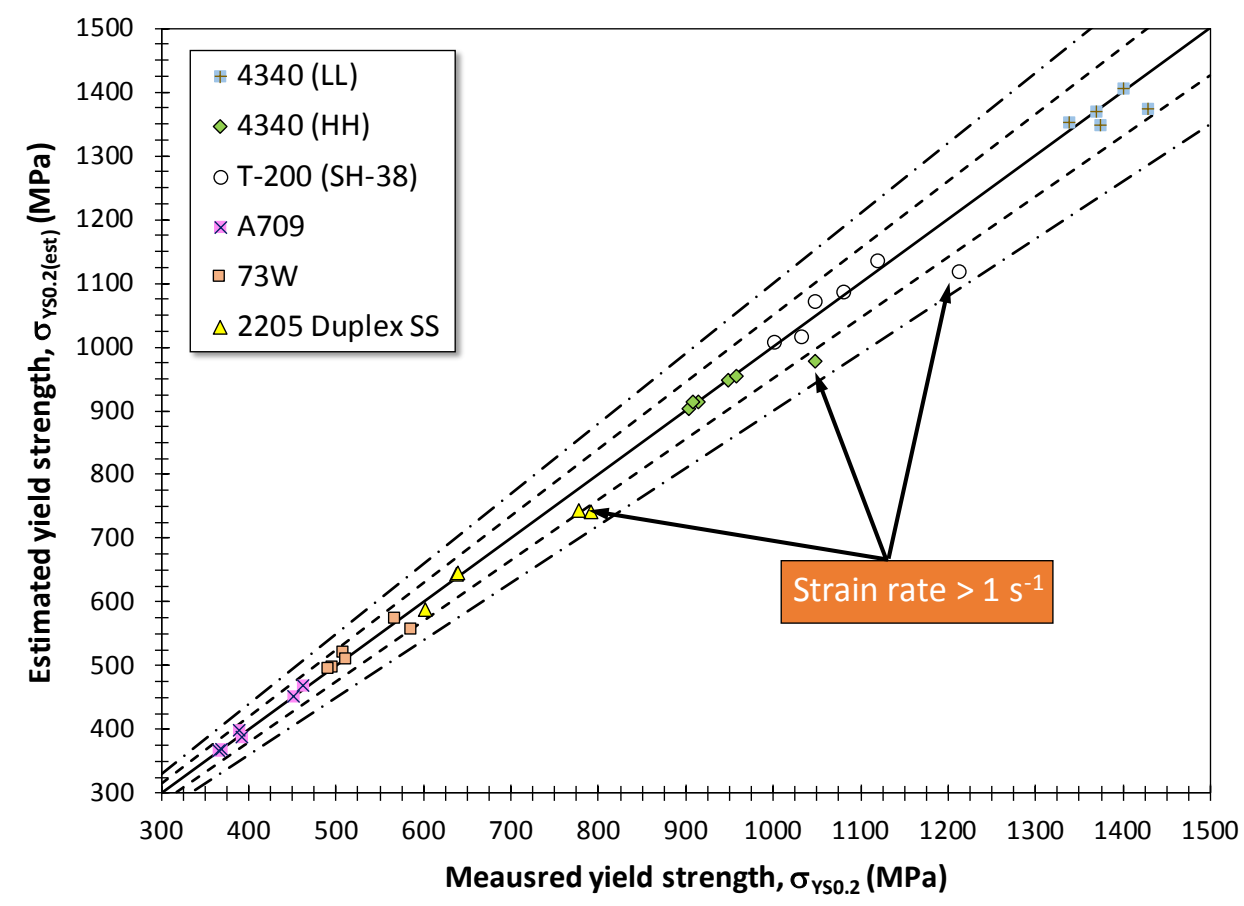

Fig. 6. Comparison between yield strength values calculated from force/elongation $\left(\sigma_{Y S 0.2}\right)$ and force/actuator displacement $\left(\sigma_{Y S 02(e s t)}\right)$ data. Dashed lines correspond to agreement within $\pm 5 \%$, and dashed/dotted lines to agreement within $\pm 10 \%$. 
For these tests, extensometer instability and slippage was often observed in the linear elastic portion of the test records, causing large uncertainty in the values of $\sigma_{Y S 0.2}$.

We therefore decided to use in this investigation only $\sigma_{Y S 0.2(e s t)}$ values for all steels, except when discontinuous yielding was observed. In the latter case, $\sigma_{Y S}=\sigma_{L Y S}$.

\subsection{Instrumented Charpy Tests}

All the instrumented Charpy tests were performed on a large-capacity impact machine (potential energy $=953.56 \mathrm{~J}$, impact velocity $=5.47 \mathrm{~m} / \mathrm{s}$ ). The machine was equipped with an instrumented striker conforming to ASTM E23 (radius of the striking edge $=8 \mathrm{~mm}$ ). All tests were performed at room temperature $\left(21^{\circ} \mathrm{C} \pm 1{ }^{\circ} \mathrm{C}\right.$ ), and most of the investigated steels exhibited fully ductile behavior (upper shelf conditions). However, three materials (4340-LL, 73W, and A709) presented unstable crack propagation events, indicating that for these steels $21^{\circ} \mathrm{C}$ lies within the ductile-to-brittle transition region.

\section{Results}

For each of the steels investigated, yield strength values were fitted as a function of strain rate (see also two examples in Fig. 8) using the following power law relationship:

$$
\sigma_{Y S}=A_{Y S}\left(\dot{\varepsilon}_{G Y}\right)^{m_{Y S}}
$$

where, for reasons already explained, $\sigma_{Y S}$ is the minimum between $\sigma_{L Y S}$ and $\sigma_{Y S 0.2(e s t)}$, and $\dot{\varepsilon}_{G Y}$ is the effective strain at the point of general yield (calculated with the 9-point average method). In Eq. (8), $A_{Y S}$ and $m_{Y S}$ are fitting coefficients and $m_{Y S}$ represents the material's yield strength strain-rate sensitivity.

The values $A_{Y S}$ and $m_{Y S}$ that we obtained by least-squares fitting are shown in Table 4 for the steels investigated, along with their respective standard errors (SE). We remark that A36 is the most strain-rate sensitive steel, while 4340-LL is the least sensitive. A strong negative correlation ( $r=-0.7882)$ between strain-rate sensitivity $\left(m_{Y S}\right)$ and quasi-static yield strength (from Table 3 ) can be observed in Fig. 7. In the figure, our results are also compared with published data on high strength/high toughness steels [22], automotive sheet steels [23], and the domain of "typical” values of $m_{Y S}$ and $\sigma_{Y S, q S}$ (quasi-static yield strength) for carbon and alloy steels [24, 25].

Table 4. Fitting coefficients for Eq. (8) obtained for the steels investigated, with corresponding standard errors (SE). NOTE: $A_{Y S}$ is the yield strength corresponding to $1 \mathrm{~s}^{-1}$.

\begin{tabular}{|ccccc|}
\hline \multirow{2}{*}{ Steel } & \multicolumn{2}{c}{$\begin{array}{c}A_{Y S} \\
\text { (MPa) }\end{array}$} & \multicolumn{2}{c|}{$m_{Y S}$} \\
\cline { 2 - 5 } & Fit & SE & Fit & SE \\
\hline A709 & 447.6 & 19.29 & 0.023 & 0.0026 \\
\hline 73W & 552.7 & 22.82 & 0.013 & 0.0025 \\
\hline 2205 Duplex SS & 730.8 & 17.69 & 0.025 & 0.0015 \\
\hline A36 & 363.8 & 19.79 & 0.041 & 0.0013 \\
\hline API X100 (or. L) & 772.2 & 20.14 & 0.006 & 0.0021 \\
\hline API X100 (or. T) & 911.9 & 39.36 & 0.007 & 0.0042 \\
\hline 4340-LL & 1385.7 & 32.57 & 0.003 & 0.0014 \\
\hline 4340-HH & 961.7 & 28.82 & 0.006 & 0.0018 \\
\hline T-200 (SH-37) & 1008.3 & 49.92 & 0.011 & 0.0027 \\
\hline T-200 (SH-38) & 1125.5 & 20.57 & 0.011 & 0.0011 \\
\hline & & & & \\
\hline
\end{tabular}




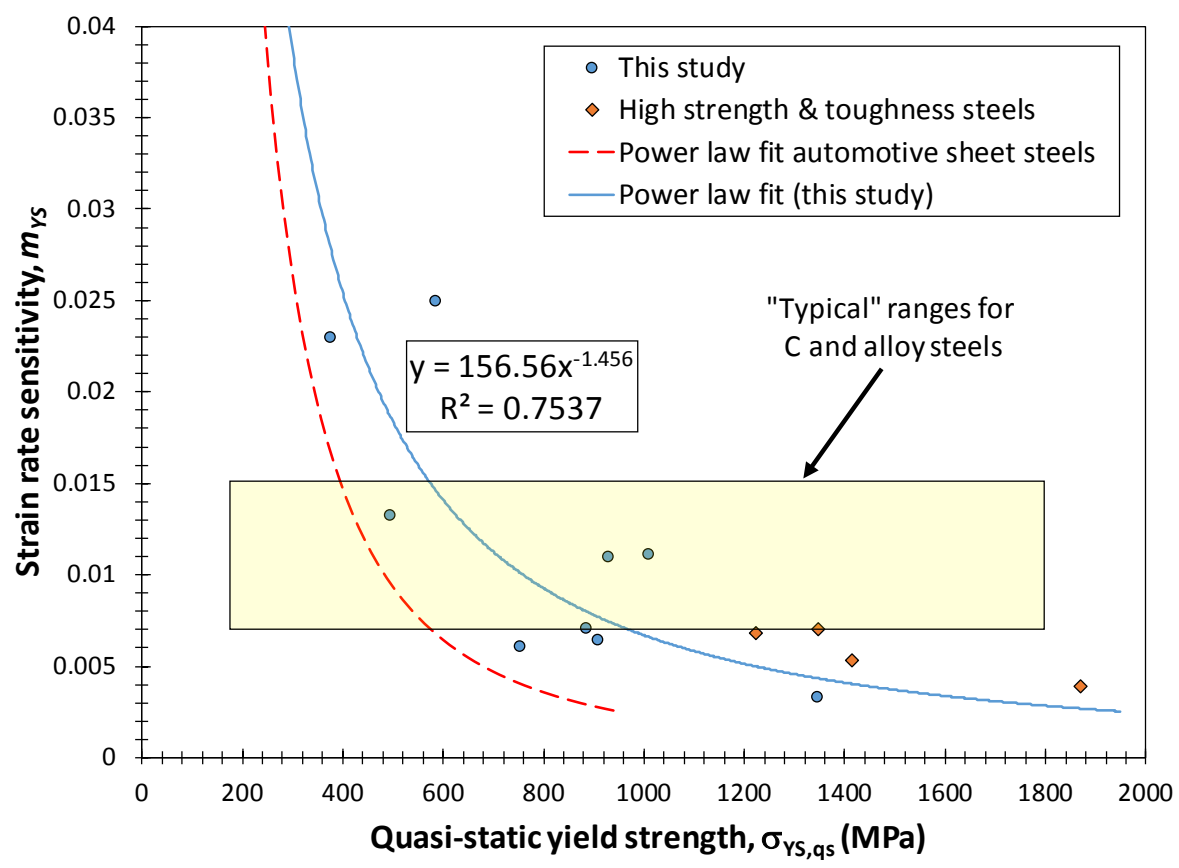

Fig. 7. Relationship between quasi-static yield strength and strain-rate sensitivity for the steels investigated. Data are fitted by a power law function, which provides the highest value of the coefficient of determination $\mathrm{R}^{2}$. Our results are also compared to literature data from various sources [22-25].

The values of force at general yield $\left(F_{G Y}\right)$ from the Charpy tests were converted into Charpy-based estimates of dynamic yield strength $\left(\sigma_{G Y, C V}\right)$ by the use of Eq. (3). The equivalent Charpy strain rate

( $\left.\varepsilon_{Y S, C V}\right)$ for every specific material was established by minimizing the sum of residuals calculated as the sum of the differences between each $\sigma_{G Y, C V}$ value and the corresponding $\sigma_{Y S}$ obtained from Eq. (8). The values of $A_{Y S}$ and $m_{Y S}$ provided in Table 4 were used in the calculations for each material.

The results obtained are summarized in Table 5 . The values in the table correspond to impact tests conducted at $5.47 \mathrm{~m} / \mathrm{s}$, and span five orders of magnitude (from $10^{-1} \mathrm{~s}^{-1}$ to $10^{3} \mathrm{~s}^{-1}$ ). This wide range is most likely due to the sensitivity of the calculated strain rates to the exact values of $\sigma_{G Y, C V}$ obtained from the Charpy tests, although the approach of minimizing square residuals, as mentioned above, should help to mitigate these effects.

Table 5. Equivalent Charpy strain rates at general yield for the steels investigated.

\begin{tabular}{|c|c|}
\hline Steel & $\begin{array}{l}\dot{\varepsilon}_{Y S, C V} \\
\left(\mathrm{~s}^{-1}\right)\end{array}$ \\
\hline A709 & 6.2 \\
\hline $73 \mathrm{~W}$ & 1.4 \\
\hline 2205 Duplex SS & 81.1 \\
\hline A36 & 131.3 \\
\hline API X100 (or. L) & 1111.1 \\
\hline API X100 (or. T) & 0.7 \\
\hline 4340-LL & 2.0 \\
\hline 4340-HH & 9.4 \\
\hline T-200 (SH-37) & 25.0 \\
\hline T-200 (SH-38) & 0.5 \\
\hline
\end{tabular}


The analyses described above are illustrated in Fig. 8, which shows data for the steels having the lowest (A36) and highest (4340-LL) yield strength.
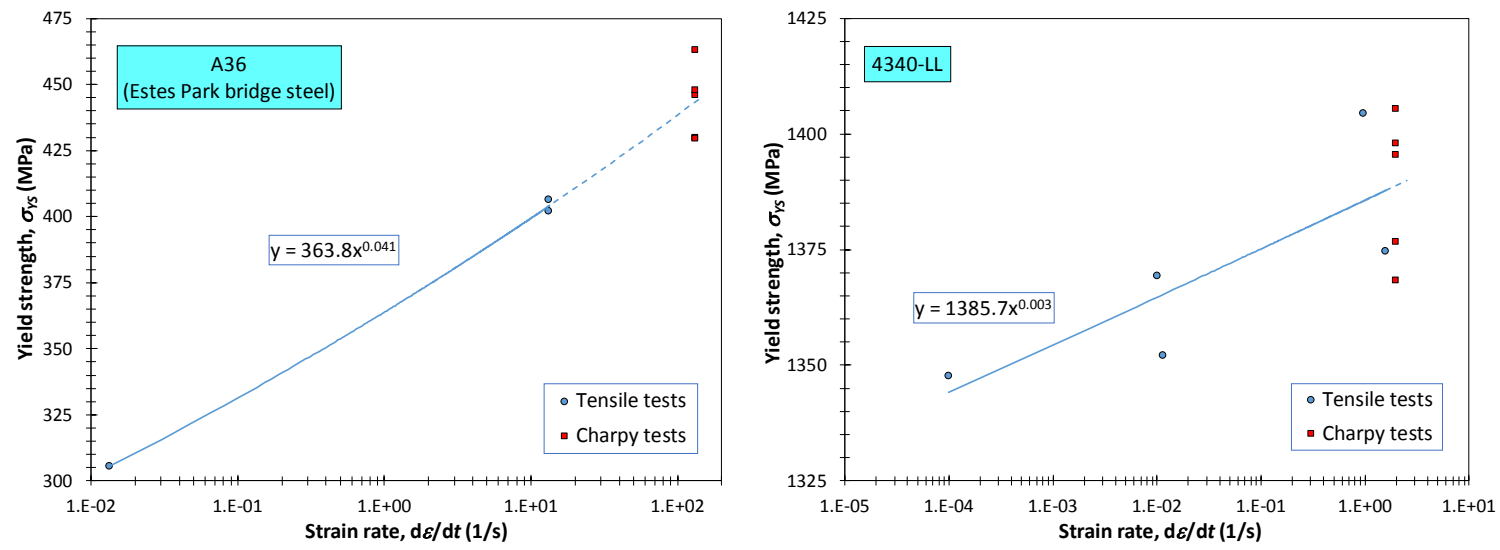

Fig. 8. Establishment of the equivalent Charpy strain rate at general yield for A36 (left) and 4340-LL (right).

We examined possible correlations between the calculated strain rates at general yield listed in Table 5 and basic mechanical properties (quasi-static yield strength and Charpy energy at RT). In addition, we have considered several additional variables, such as:

- $\quad$ strain-rate sensitivity at general yield $\left(m_{Y S}\right)$,

- $\quad$ impact velocity at general yield $\left(v_{G Y}\right)$,

- Charpy energy corresponding to ductile crack initiation $\left(W_{i}\right)^{2}$,

- $\quad$ Charpy energy corresponding to ductile crack propagation $\left(W_{p}\right)^{3}$, and

- $\quad$ ratio between propagation and initiation Charpy energies $\left(W_{p} / W_{i}\right)$.

The quality of the correlations, quantified by the Pearson product-moment correlation coefficient ${ }^{4} r$, is summarized in Table 6.

Table 6. Degree of correlation between calculated strain rate at general yield ( $\left.\dot{\varepsilon}_{Y S, C V}\right)$ and various material properties.

\begin{tabular}{|ccc|}
\hline Material property & $r$ & Degree of correlation \\
\hline Quasi-static yield strength, $\sigma_{Y S, q-s}$ & -0.077 & Extremely poor \\
\hline Charpy absorbed energy, $K V$ & 0.700 & Quite strong \\
\hline Strain-rate sensitivity, $m_{Y S}$ & -0.160 & Poor \\
\hline Impact velocity at $G Y, v_{\mathrm{GY}}$ & 0.208 & Poor \\
\hline Initiation absorbed energy, $W_{\mathrm{i}}$ & 0.275 & Quite poor \\
\hline Propagation absorbed energy, $W_{\mathrm{p}}$ & 0.730 & Strong \\
\hline$W_{p} / W_{i}$ & 0.747 & Strong \\
\hline
\end{tabular}

\footnotetext{
${ }^{2}$ According to both analytical [11] and experimental $[15,16]$ published studies, ductile crack initiation in an instrumented Charpy test occurs approximately halfway between general yield and maximum force. The absorbed energy at initiation, $W_{i}$, is therefore calculated as the average of the absorbed energy at general yield $\left(W_{g y}\right)$ and at maximum force $\left(W_{m}\right)$.

${ }^{3}$ The absorbed energy corresponding to crack propagation is simply given by the total absorbed energy minus the initiation energy, i.e., $W_{p}=K V-W_{i}$.

${ }^{4}$ The Pearson product-moment correlation coefficient [26] returns a value between +1 and -1 inclusive, where +1 indicates a perfect positive correlation, 0 no correlation, and -1 perfect negative correlation. A correlation is positive if there is direct proportionality between $Y$ and $X$, negative if there is inverse proportionality between $Y$ and $X$.
} 
The strongest correlations $(r \geq 0.7)$ have been observed with total absorbed energy $(K V)$, propagation energy $\left(W_{p}\right)$, and the ratio between propagation and initiation energies $\left(W_{p} / W_{i}\right)$. The correlations are illustrated in Fig. 9, where the three data sets have been linearly fitted. Note that a linear fit was found to give the highest degree of correlation (expressed in terms of the coefficient of determination $R^{2}$ ) with respect to other equations (power law and exponential).

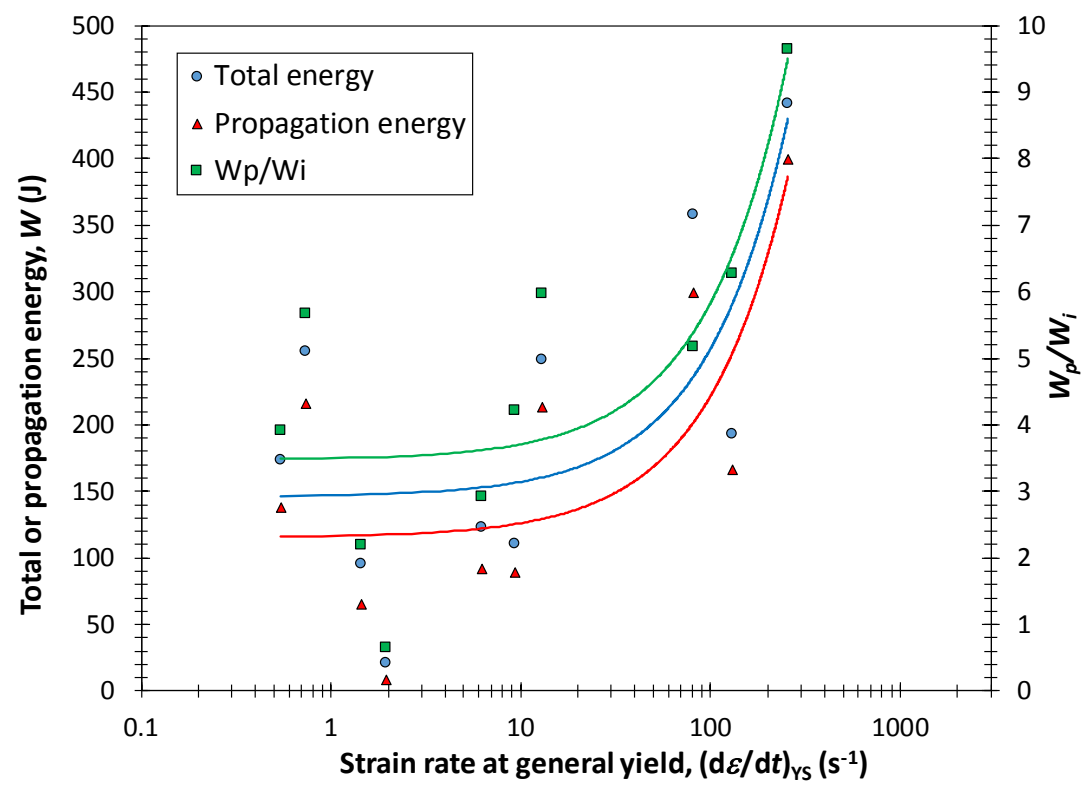

Fig. 9. Correlations between strain rates at general yield and total energy, propagation energy, and $W_{p} / W_{i}$ ratio.

\section{Comparison with Strain Rate Estimates from ASTM E1820 and ASTM E1921}

As previously explained, both ASTM E1820-15a and ASTM E1921-15a include relationships [14, 15] that can be used to derive estimates of the equivalent uniaxial strain rate for the obtainment of the dynamic tensile properties to be used in the analysis of fracture toughness tests at elevated loading rates (Eqs. (5)-(7) in this paper).

The characteristic time used in the estimates is the time to the onset of fracture instability or to the initiation of stable crack extension (E1820, Annex A14), the time corresponding to the elastic limit in the test record (E1820, Annex A17), or the time to cleavage (E1921).

For the instrumented Charpy tests performed in this work, two estimated strain rate values have been calculated: $\dot{\varepsilon}_{\text {est, } 1}$ (using the time at general yield $t_{g y}$, which effectively corresponds to the limit of the elastic portion) and $\dot{\varepsilon}_{e s t, 2}$ (using the time corresponding to the onset of stable crack extension, $t_{i}=\left(t_{g y}+t_{m}\right) / 2[12$, 13]). Calculated ( $\dot{\varepsilon}_{Y S, C V}$, from Charpy-based $F_{G Y}$ values - as given in Table 5) and estimated ( $\left.\dot{\varepsilon}_{\text {est }, 1}, \dot{\varepsilon}_{\text {est }, 2}\right)$ values of strain rate are compared in Table 7 and Fig. 10. The values of the estimated strain rates for each material have been obtained by averaging the values calculated for all the Charpy tests performed. The lack of correlation between calculated and estimated strain rates ( $r=0.0176$ for $\dot{\varepsilon}_{\text {est }, 1}$ and $r=-0.2003$ for $\left.\dot{\varepsilon}_{\text {est }, 2}\right)$ indicates that Eqs. (5)-(7), proposed in Refs. [14, 15] for cracked specimens, do not work well for notched Charpy specimens.

Fig. 10 shows that the effective spread of the calculated strain rates $\dot{\varepsilon}_{Y S, C V}$ (five decades) is much larger than the spread of the values estimated by means of Eqs. (5)-(7) (three decades). 
Table 7. Calculated and estimated strain rates for the investigated steels.

\begin{tabular}{|c|c|c|c|}
\hline Steel & $\begin{array}{c}\dot{\varepsilon}_{\text {YS }, C V} \\
\left(\mathrm{~s}^{-1}\right)\end{array}$ & $\begin{array}{c}\dot{\varepsilon}_{\text {est }, 1} \\
\left(\mathrm{~s}^{-1}\right)\end{array}$ & $\begin{array}{c}\dot{\varepsilon}_{\text {est }, 2} \\
\left(\mathrm{~s}^{-1}\right)\end{array}$ \\
\hline A709 & 6.2 & 70.9 & 8.7 \\
\hline 73W & 1.4 & 95.9 & 13.8 \\
\hline 2205 Duplex SS & 81.1 & 50.2 & 10.9 \\
\hline A36 & 131.3 & 74.7 & 8.0 \\
\hline API X100 (or. L) & 1111.1 & 104.2 & 19.5 \\
\hline API X100 (or. T) & 0.7 & 153.3 & 25.7 \\
\hline 4340-LL & 2.0 & 127.8 & 89.3 \\
\hline $\mathbf{4 3 4 0 - H H}$ & 9.4 & 95.6 & 43.5 \\
\hline T-200 (SH-37) & 25.0 & 83.6 & 30.2 \\
\hline T-200 (SH-38) & 0.5 & 87.4 & 35.4 \\
\hline
\end{tabular}

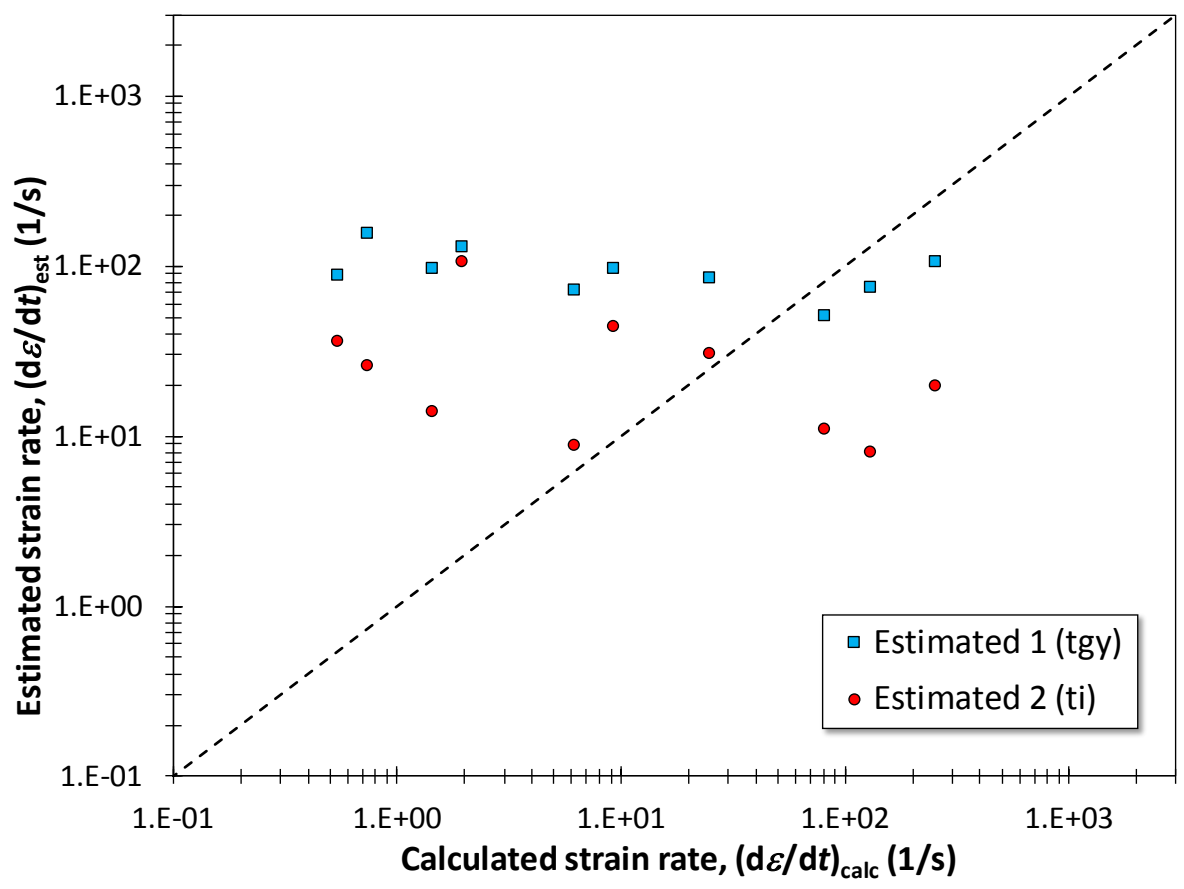

Fig. 10. Comparison between estimated and calculated strain rates.

\section{Conclusions}

An investigation was conducted at NIST in Boulder Colorado, consisting of tensile tests performed at different strain rates and instrumented Charpy tests on specimens from 10 different materials, covering a wide range of mechanical properties (quasi-static yield strengths between $378 \mathrm{MPa}$ and $1348 \mathrm{MPa}$, Charpy energies between $21 \mathrm{~J}$ and $441 \mathrm{~J}$ ). The specific objective of this study, described in this paper, was the assessment of the equivalent tensile (uniaxial) strain rate for a typical Charpy test conducted at $5.5 \mathrm{~m} / \mathrm{s}$.

For each material, the Charpy-equivalent strain rate at general yield was calculated by minimizing the residuals between the estimates of dynamic yield strength provided by a well-established relationship published by Server in 1978 and a power-law regression of yield strength values obtained from tensile tests as a function of strain rate.

The results obtained indicate that the equivalent strain rate for a Charpy test is far from materialindependent, and can be very different from material to material. For the ten materials considered in this 
work, we obtained strain rates ranging between $10^{-1} \mathrm{~s}^{-1}$ and $10^{4} \mathrm{~s}^{-1}$. We investigated potential relationships between calculated strain rates and various material properties, but reasonable correlations $(r \geq 0.7)$ were only found with Charpy energy, propagation energy, and the ratio between initiation and propagation energy.

\section{Acknowledgments}

The tensile tests on A36, SH-37 and X100 were conducted by NIST in collaboration with Andrew Douglas and Kip Findley from Colorado School of Mines (Golden, CO). Their collaboration is gratefully acknowledged, as well as the numerous fruitful technical discussions.

\section{References}

[1] Dunn BW (1897) A photographic impact testing machine for measuring the varying intensity of an impulsive force. $J$ Frankl Inst 144(5):321-348. http://dx.doi.org/10.1016/S0016-0032(97)90018-1

[2] Russell SB (1898) Experiments with a new machine for testing materials by impact. Trans Am Soc Civ Eng 39(826):237-250.

[3] Manahan M \& Siewert T (2006) The history of instrumented impact testing. J ASTM Int 3(2). http://dx.doi.org/10.1520/JAI12867

[4] Server WL (1978) General yielding of Charpy V-Notch and precracked Charpy specimens. J Eng Mater-T Asme 100(2):183188. http://dx.doi.org/10.1115/1.3443469

[5] Green AP \& Hundy BB (1956) Initial plastic yielding in notch bend tests. J Mech Phys Solids 4(2):128-144 http://dx.doi.org/10.1016/0022-5096(56)90085-0

[6] Green AP (1953) The plastic yielding of notched bars due to bending. Q J Mech Appl Math 6(2):223-239. http://dx.doi.org/10.1093/qjmam/6.2.223

[7] Lianis G \& Ford H (1958) Plastic yielding of single notched bars due to bending. J Mech Phys Solids 7(1):1-21. http://dx.doi.org/10.1016/0022-5096(58)90035-8

[8] Wilshaw TR (1966) Deformation and fracture of mild steel Charpy specimens. J Iron Steel I 204:936-942.

[9] Rau CA, Jr (1967) The effect of drilled holes on notch toughness. PhD thesis, Stanford University (Stanford, CA).

[10] Wullaert RA (1969) The effect of nickel on the microstructure and mechanical properties of ferritic steels. PhD thesis, Stanford University (Stanford, CA).

[11] Norris DM (1979) Computer simulation of the Charpy V-Notch toughness test. Eng Frac Mech 11(2):261-274. http://dx.doi.org/10.1016/0013-7944(79)90003-1

[12] Tvergaard V \& Needleman A (1986) Effect of material rate sensitivity on failure modes in the Charpy V-notch test. J Mech Phys Solids 34(3):213-241. http://dx.doi.org/10.1016/0022-5096(86)90019-0

[13] Tvergaard V \& Needleman A (1988) An analysis of the temperature and rate dependence of Charpy V-notch energies for a high nitrogen steel. Int J Frac 37(3):197-215. http://dx.doi.org/10.1007/BF00045863

[14] Rossoll A, Berdin C, Forget P, Prioul C, Marini B (1999) Mechanical aspects of the Charpy impact test. Nucl Eng Des 188(2):217-229. http://dx.doi.org/10.1016/S0029-5493(99)00017-5

[15] Fabry A, van Walle E, Chaouadi R, Wannijn J-P, Verstrepen A, Puzzolante J-L, Van Ransbeeck Th, Van de Velde J (1993) RPV steel embrittlement: damage modeling and micromechanics in an engineering perspective. IAEA/OECD Specialists' Meeting on Irradiation Embrittlement and Optimization of Annealing (Paris, France).

[16] Chaouadi R \& Fabry A (2002) On the utilization of the instrumented Charpy impact test for characterizing the flow and fracture behavior of reactor pressure vessel steels. European Structural Integrity Society, eds François D \& Pineau A (Elsevier), Vol 30, pp 103-117. http://dx.doi.org/10.1016/S1566-1369(02)80011-5

[17] Irwin GR (1964) Crack-toughness testing of strain-rate sensitive materials. J Eng Power 86(4):444-450. http://dx.doi.org/10.1115/1.3677632

[18] Shoemaker AK (1969) Factors influencing the plane-strain crack toughness values of a structural steel. J Basic Eng 91(3):506511. http://dx.doi.org/10.1115/1.3571171

[19] Portevin A \& Le Chatelier H (1923) Sur un phénomène observé lors de l'essai de traction en cours d'alliages de transformation. C R Acad Sci Paris 176:507-510.

[20] Abbadi M, Hähner P, \& Zeghloul A (2002) On the characteristics of Portevin-Le Chatelier bands in aluminum alloy 5182 under stress-controlled and strain-controlled tensile testing. Mat Sci Eng A337(1-2):194-201. http://dx.doi.org/10.1016/S0921-5093(02)00036-9

[21] Hertzberg RW, Vinci RP, Hertzberg JL (2012) Deformation and fracture mechanics of engineering materials (John Wiley \& Sons, Inc., Hoboken, NJ), 5th Ed.

[22] Boyce BL, Crenshaw TB, Dilmore MF (2007) The strain-rate sensitivity of high-strength high-toughness steels. (Sandia National Laboratories, Albuquerque, NM), Sandia Report S2007-0036.

[23] Larour P (2010) Strain rate sensitivity of automotive sheet steels: influence of plastic strain, strain rate, temperature, microstructure, bake hardening and pre-strain. Dissertation for the Degree of Doctor in Engineering Sciences, RWTH Aachen University (Aachen, Germany).

[24] ASM ready reference: properties and units for engineering alloys (1997) (ASM International, Materials Park, Ohio). 
[25] eFunda. General properties of steels. Available at: http://www.efunda.com/materials/alloys/alloy_home/steels_properties.cfm [Accessed March 30, 2016].

[26] Pearson K (1895) Note on regression and inheritance in the case of two parents. Proc of the Royal Society of London 58(347352):240-242. http://dx.doi.org/10.1098/rspl.1895.0041.

About the author: Enrico Lucon is a Materials Engineer in the Applied Chemicals and Materials Division of the National Institute of Standards and Technology (NIST) in Boulder, Colorado since 2010. Originally from Milan (Italy), he was previously at CISE Milan (1986-1998) and at SCK•CEN, the Belgian Nuclear Research Center (1998-2010). The National Institute of Standards and Technology is an agency of the U.S. Department of Commerce. 